\title{
The Effect of Roads on the Movement of Large and Mid-sized Mammals
}

\author{
Marcis Saklaurs ${ }^{1}$, Raivis Baltmanis ${ }^{2},{ }^{1-2}$ Latvia University of Agriculture
}

\begin{abstract}
Infrastructure development is one of the major threats to biodiversity in the forest. Roads are barriers which restrict the movement of animals. It is therefore urgent to explore characteristics of mammal life associated with forest road crossings. Mammals cross forest roads very rarely compared to the intensity of their movement within the forest. Data sets were created by observing footprints in the snow. The study concludes that forest roads are not an insurmountable obstacle for medium and large mammals.
\end{abstract}

Keywords - Effect, forest roads, large and medium size mammals, movements.

\section{INTRODUCTION}

Large (moose - Alces alces, roe deer - Capreolus capreolus, wild boar - Sus scrofa) and medium size (gray wolf - Canis lupus, domestic dog - Canis lupus familiaris, Eurasian lynx - Lynx lynx, racoon dog - Nyctereutes procyonoides, red fox - Vulpes vulpes, European hare - Lepus europaeus) mammals are typical for Latvian fauna with stable populations of these species [1]. Basically the largest proportion of their lives, these species spend in the woods searching for food; however, they also spend some time in field margins, scrub areas and river floodplains.

Large and medium size mammal habitat - the forest occupies 3.2 million ha of Latvia [2], which is half of the entire territory of the country. The Latvian forest sector plays a vital role in the national economy, in 2010 it accounted for $5.3 \%$ of gross domestic product [3]. To ensure sustainable production, stable resources such as timber are required throughout the year. An average of $380 \mathrm{~km}$ road surfacing of new forest roads every year has been built and existing roads are maintained or reconstructed by the Joint Stock Company "Latvian State Forests" (LVM = LSF), which is responsible for managing of more than a half of the total Latvian forest area. Overall, Latvian forest roads (managed by LVM) are characterized by a linear arrangement, which is like a barrier restricting the movement of animals [4].

Forest road construction causes forest fragmentation, which is due to have an impact on biodiversity, including on large and medium size mammals migration and movement [5], [6], [7], [8], [9] and [10]. Development of infrastructure is considered to be one of the major threats to biodiversity, especially in regard to rare and protected species, their movement and migration [11]. If the roads do not directly affect mammals, they still willingly choose to avoid the immediate vicinity of the road area and choose less disturbed areas as their place of residence. This is mostly due to everyday road disorders such as artificial barriers, traffic danger and pollution, as well as noise [12], [13], [14]. Various other studies have indicated that the development of the road network has had a significant impact not only on large and medium size mammals, but also on birds [15], [16], [17], amphibians and reptiles [18], [19], [20].

Research on the influence of forest roads on wild animals clearly states that the influence is significant and almost always negative [21], [22], [23], [24], [25], [26], [27]. However, it must be noted that the influence of forest roads on the migration of large and average-size mammals [28], [29], [30], [31] influenced by the development of the infrastructure in the forest, has been researched insufficiently. The research in this article comprises an analysis of migration of animals in Latvian forests that have received relatively little attention until now. The habits and migration of the abovementioned mammals have also been researched in a scanty manner with no analysis of dedicated data to enable to identify the precise influence of the forest roads [32], [33], [34], [35].

With reference to the abovementioned, the following research hypothesis is put forward: forest roads have significant impact on the movements of large and medium size mammals. The objective of the research: to identify the effects of forest roads on the movement of mammals. During the research, data analysis was conducted to compare observations, using the mammalian species as the basis for the evaluation. Thus it will be possible to determine whether there are any differences between the features of the movement and their intensity among different species of animals.

\section{METHODS}

\section{A. General Study Design}

The open field work was carried out in the Salacgriva District (Latvia) in the area of an existing forest tract (Fig. 1). New forest road construction, as well as the maintenance of existing forest roads, was carried out in the forest tract in question. The central part of the forest tract is comprised of a forest under the ownership of LSF. The structure of the property also includes forests belonging to other owners; however these forest plots are mostly located along the external borders of the array, and do not directly affect the study area.

The total forest landscape consists of commercial forests, the objects of infrastructure with some small areas - glades. Animal species used in the study inhabit the relevant distribution area and are known to have stable (Canis lupus, Lynx lynx) and growing (Alces alces) populations. Lepus europaeus distribution in the study area is assessed as low, as 
the typical area of the speciesfields with forests rather than a continuous forest massif.

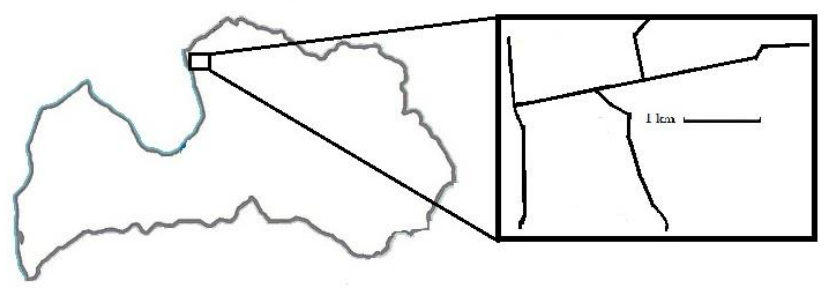

Fig. 1. Latvia. Forest road network in Salacgriva district.

Forest road density is relatively low, thus preventing the accommodation of appropriate control lines in the survey area. Natural roadways were not considered forest roads in the current study. The researched territory occupied $5.9 \mathrm{~km}^{2}$ of the total forest. It includes the following routes: Kraukli way $1.98 \mathrm{~km}$, Purvmali track - $2.50 \mathrm{~km}$ and Vedamurga way $1.42 \mathrm{~km}$. The density of the forest road in the study area is $1 \mathrm{~km}$ per 100 ha which is lower than the average ratio for the forests managed by LSF. The reason for the lower ratio in this case is due to the existence of unpaved roads within the area of the study, which is necessary for timber transport.

For the purposes of the study, the forest roads selected were such that directly adjoin the forest without barriers (e.g. open water, fences, steep slopes) along their sides that might affect the study results. On the onset of the study, a gravel pit of 1.5 ha that adjoined the road Kraukli and stretched as a $250-$ meter band was set up in the forest of research. As the open field work was done in the winter (January to March) in 2012, 2013 and 2014, and gravel excavation - in the summer, it did not directly affect the mammals and it is also to be mentioned that the pit's area is less than the average clear-felling in the forests managed by LSF. Taking into the consideration the fact that it was determined that the pit is less likely to be a nuisance, the decision was made to continue counting footprints in that area.

Forest roads are used for forestry work, including timber transport and provision of mobility. As forest roads have specially built connections to local roads, they are also used by local residents for social interests such as berry and mushroom picking as well as hunting, bird watching, transportation, access to their own properties, etc.

\section{B. Plot Dimensions}

For each forest road section where the study was conducted, a specially arranged control parallel line was established. The control lines were established from $800 \mathrm{~m}$ to $900 \mathrm{~m}$ from the road, depending on their position within the field. According to the advice given by M. P. Huisjer and P. J. M. Berger in their study on small mammal movement, it is advisable to choose the control lines as far as possible from the forest path, taking into the account the density of the network of the roads and the existing capability, therefore a distance of at least $800 \mathrm{~m}$ whenever possible is recommended [36].

For the current study, the function of the control lines forest tract of the paths (the on-site dividing belt of the compartments) was adopted. Using the firebreaks it was achieved that the control lines are fixed and constant in repeated studies as well as their length are also constant. This means that forest roads as well as firebreaks are equal in length and are parallel (except one control plot), thus maintaining a consistent distance one line from the other (Fig. 2). The first study area - was a 1870-meter-long forest road, the second study area $-720 \mathrm{~m}$ and the third area of the study $-730 \mathrm{~m}$. For all roads used in the study, equally long lines of control were developed. The total survey distance was $6640 \mathrm{~m}$.

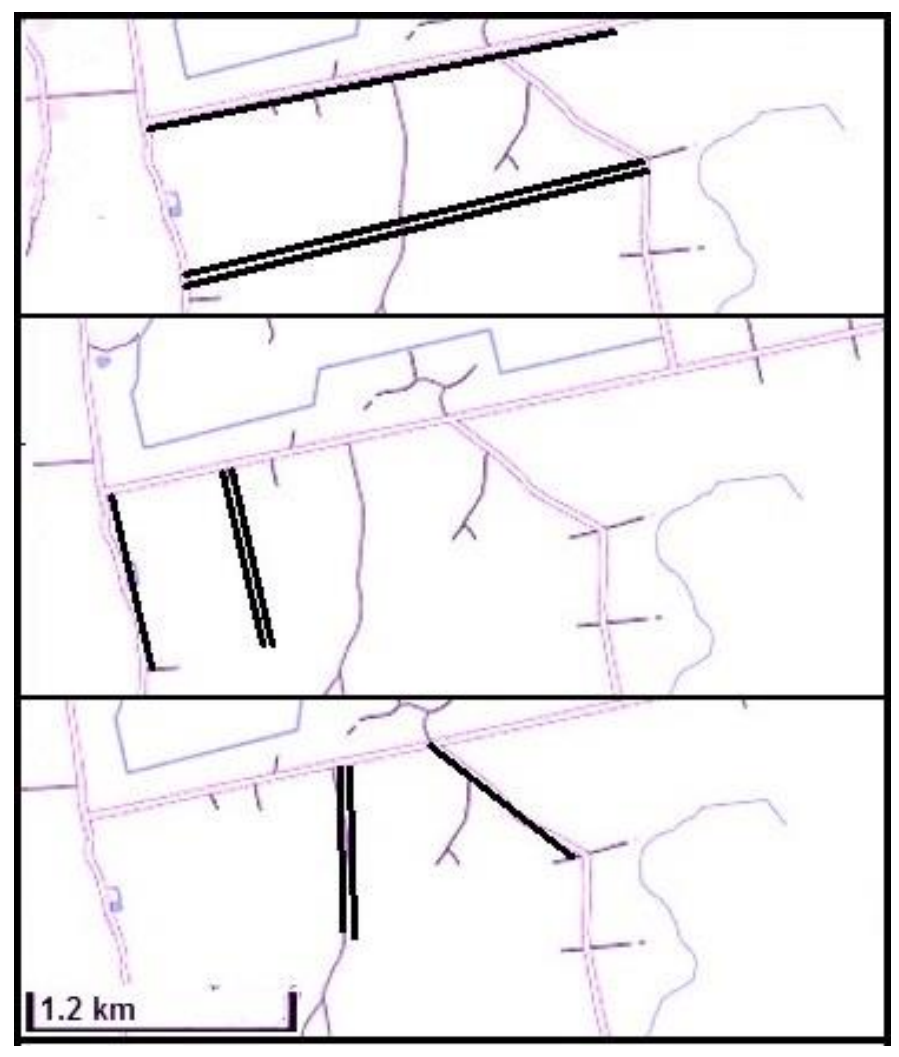

Fig. 2. Study area. One line shows forest road, two lines - control.

\section{Footprints}

The observation of large and medium size mammal footprints was carried out to enable the determination of the intensity of movement and migration of the animals in the area in question. The footprints were counted when the ground was covered with snow. Only the footprints which were no older than two weeks were taken into the account (the age of the footprints were determined by measuring the level of precipitation). In 2014 the open field work was carried out in two-day-old snow as the amount of snow in the winter of 2014 was limited. In December of 2013 as well as January, February and March of 2014, the average depth of snow cover in Latvia was only $1 \mathrm{~cm}$ [36]. The abovementioned conditions impaired the compilation of data as the shallow coverage of snow did not make it possible to acquire reliable results. Up to March 18 of 2014, the research area was covered with $10 \mathrm{~cm}$ of settled snow. On March 19 it was possible to detect the movement of animals. It is crucial for the research to perform 
the observation of the forest road and the control line on the same day in order to prevent the occurrence of additional footprints.

Large and medium size mammals (Alces alces, Capreolus capreolus, Sus scrofa, Canis lupus, Canis lupus familiaris, Lynx lynx, Nyctereutes procyonoides, Vulpes vulpes, Lepus europaeus) were listed in the study. Large predators (Canis lupus, Canis lupus familiaris and Lynx lynx) were included into a single group to rule out errors in identification of the footprints, which may occur in loose snow whilst crossing the control lines with high ground vegetation density (Vaccinium myrtillus and Vaccinium vitis - idaea shrub). Similarly, small carnivores (raccoon dog and red foxes) were grouped in a single group. An uncharacteristic forest species - domestic $\operatorname{dog}$ (Canis lupus familiaris) was included in observations, it is connected with the peculiarities of the species as it periodically travels in Latvian woods when it strays from its home.

Sus scrofa footprints were accounted using two methods. If the forest road or a control line was crossed by one individual, it was relevantly ticked as one animal. If footprints of a group of wild boars in which (in the majority of cases) the animals followed one another were found, this was considered as one group, without determining the precise number of animals in the group. The number of animals in some groups can range up to 3 (number is based on biology of species and personal observations at wild boar feeding places) individuals in the study area.

Small mammal (red squirrel - Sciurus vulgaris, European pine marten - Martes martes, beech marten - Martes foina, stoat - Mustela erminea and European badger - Meles meles) footprints were also found but their track record is not used in this study due to the complexity of identification of these footprints in deep snow and the vagueness in their movements as some of the species use the canopy of the trees.

\section{Data Analysis}

First it was essential to check in the analysis of data, whether factors such as the year of observation and the difference in species, the footprints of which were observed, may have significant impact on the migration behaviour of the mammals. For this purpose, the analysis of variance (ANOVA) was used. Before this test was carried out, the author of the research determined that the number of observed footprints did not vary much compared to the control fields. Therefore, the data of the whole territory of the control fields were combined and united into one set, to which then the analysis of variance to determine if any of the above mentioned factors significantly influenced the movement of mammals was applied.

Dispersion analysis led to the conclusion that the year of observation had no significant effect on the mammalian movement patterns, so this factor was further excluded from the further analysis. In other words, the data set that enabled the author to carry out the analysis of variance to determine the effect of species on their mobility patterns, disregarding the year of the observations or the site (control fields) was obtained. The analysis of the confirmed hypothesis that the species of the animals had a significant impact on their mobility patterns on forest roads and firebreaks $(p<0.05)$.

Data analysis gave rise to another hypothesis, which claims that mammals cross the firebreaks more than forest paths. Prior to that, the analysis of variance had been carried out. It indicated that the year of observation had no significant effect on the quantities of the observed mammalian footprints. Therefore, the data collected in all years were combined together in a single set, grouping them by species of mammals. Then, using the acquired data set, the comparison of the number of footprints left on the firebreaks and on the forest roads was performed applying the t-test.

\section{RESULTS}

During the study, 529 footprints of animals were identified (Fig. 3). In the first two years of study (2012 and 2013), the number of observed footprints of animals was relatively similar namely 223 and 217. However, during the observations made in the spring of 2014 only 89 footprints were found. This was due to the scarcity of the snow and the fact that it is possible to detect the footprints left by the animals one or two days at most in the temporary snow. The initial findings showed that the majority of the footprints of the mammalian were found on the forest firebreaks, which corresponded to the first control field $-65 \%$; the second $64 \%$, and the third $-81 \%$ respectively of the total number of the detected footprints. The absolute dominance of Capreolus capreolus was observed both on the forest firebreaks and forest roads. In fact, this was explained by the migration of species, their feeding and living habits. The abovementioned species often acquires its food in direct proximity of the roads that can probably be explained by thinner settling of the snow enabling the animals to procure nutrition and escape from predators.

Similarly, when the animal footprints were recorded, it could be observed that the sides of the firebreaks or the firebreaks themselves were frequently chosen as beddings as visually it could be noticed that there was denser verdure with the shrubs of different species. Shrubs are an important food supply for Capreolus capreolus in winters. Similarly like it is with the forest roads, the vegetation that grows on the firebreaks and their edges is less effected by competition with tree-plants for light and moisture.

Large carnivores and Lepus europaeus were found in relatively few cases or were not detected at all, due to the vastness of the territory inhabited by an individual or inferior density of the population. Although the data collected on large carnivores were small in number, they still demonstrated the existence of this species in the forest as also gave us insight on the trends of movement or migration, as it was shown by the data that had been collected within three years. In other words, in all the cases observed $64 \%$ of footprints were recorded on the forest tract. But at the same time, the abovementioned species groups had crossed forest paths thus confirming their migration and movements. 


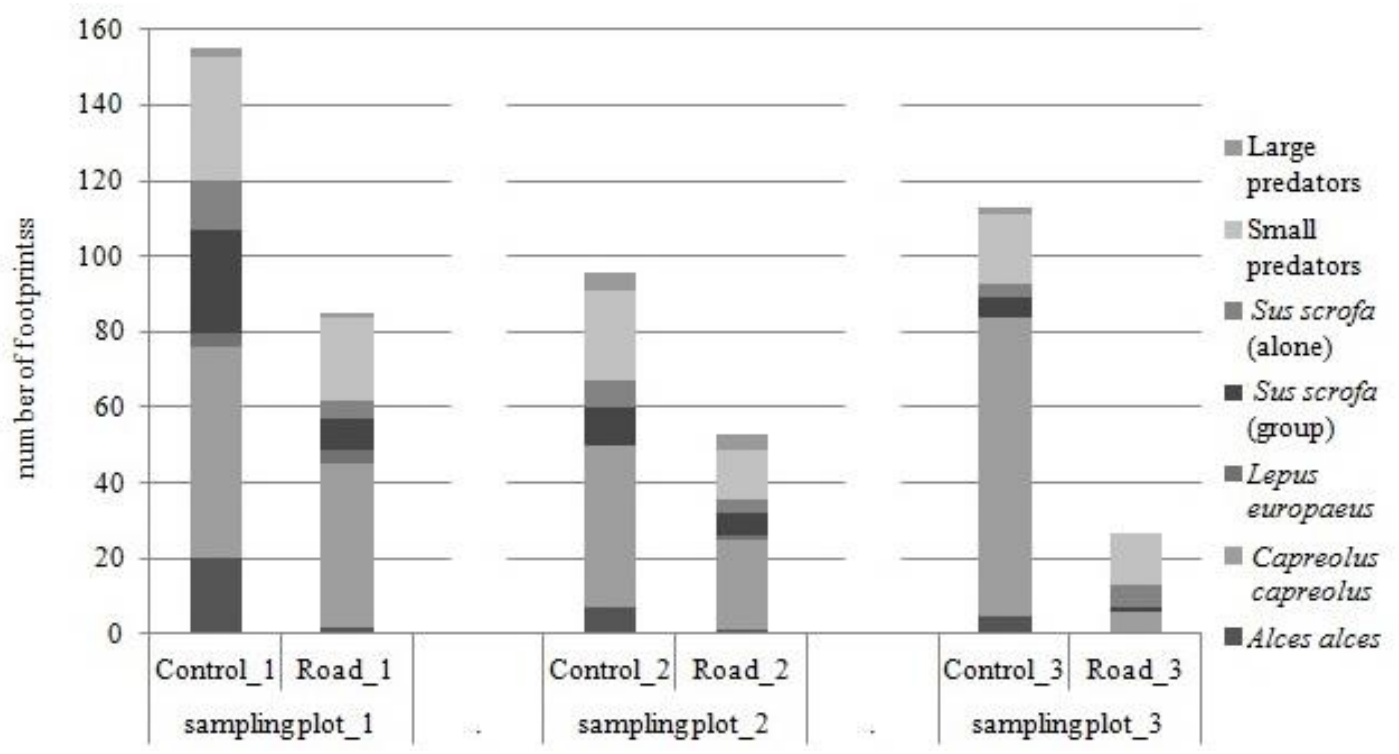

Fig. 3. Animal-footprint observation over the years and observation numbers.

The results clearly indicate that the largest mammal that inhabits Latvian forests - Alces alces was reluctant to cross the forest roads. Only $9 \%$ of Alces alces crossed the forest road, otherwise they spent their life cycle within the forest tract. Although Alces alces is considered to be the largest wild animal and it would have no difficulty in crossing the forest road, i.e. no difficulties to overcome, the species prefers to be discreet and not to reveal its presence in the forest. This confirms that the species periodically settles down to live in one place - in the part of the forest tract and leaves it only if external circumstances change or a sudden disruption occurs.

Sus scrofa observations suggest that specimens migrate both alone and in groups but in no cases would they choose to cross forest roads. They would rather make movement within the forest. Accordingly, $74 \%$ (group) and $62 \%$ (single) observation cases were recognized on the forest firebreaks.

Firstly the influence of the set of factors (the time of the survey, species) on the results of the study was determined. whilst carrying out the analysis of variance (Table I) the author found out that there was no significant difference between the footprints and the particular year of observation, so it was possible to use the data without performing the elimination and systematization of time chart (all $p>0.05$ ). However, by consolidating the number of footprints left by different species, it was discovered that the influence of various species indicated onto the significance of the results of the current study ( $p<0.05$ in four places).

TABLE I

INFLUENCE OF FACTORS ON FOOTPRINTS OF ANIMALS IN DIFFERENT CASES OF OBSERVATION (P VALUES)

\begin{tabular}{|l|c|c|c|c|c|c|}
\hline Factor & Cont._1 & Road_1 & Cont._2 & Road_2 & Cont._3 & Road_3 \\
\hline Year & 0.05 & 0.77 & 0.29 & 0.63 & 0.47 & 0.11 \\
\hline Species & 0.0514 & $\mathbf{0 . 0 0 0 5 0 2}$ & $\mathbf{0 . 0 2 9 9}$ & $\mathbf{0 . 0 0 9 5 1}$ & $\mathbf{0 . 0 1 2}$ & 0.0916 \\
\hline
\end{tabular}

Performing t-test analysis (Table II), observing the years of survey and the animal footprints it can be noticed that there is a significant difference between the number of footprints of large and medium size mammal footprints on the forest roads and on the firebreaks in the first two years of observations. The third observation year shows no significant difference between the number of footprints on the forest roads and on the firebreaks $(p>0.05)$.

TABLE II

INFLUENCE OF THE FOREST ROADS AND FIREBREAKS ON ANIMALS (P VALUES)

\begin{tabular}{|l|l|l|l|l|l|l|}
\hline & Cont._1 & Road_1 & Cont._2 & Road_2 & Cont._3 & Road_3 \\
\hline Species & P value & $\mathbf{0 . 0 2 5 6 4}$ & P value & $\mathbf{0 . 0 3 5 1 8}$ & P value & 0.08479 \\
\hline
\end{tabular}

Looking at the trends in each individual species' movement the observations show that there is no significant difference between forest roads and forest firebreaks when the footprints are divided by species or groups and each study observation site in particular (Table III). The results show that the number of observations is essential. As an example, Lepus europeus and large predators, which have the highest $P$ value and the lowest figures in the number of observations, can be mentioned in comparison with Capreolus carpeoulus, which has the lowest $P$ value and the highest figures in the number of observations.

However, summarizing the data compiled within three years, it is evident that the effects of forest roads is essential only for Capreolus capreolus movement $(P=0.04)$. The number of identified footprints of deer comprises $47.4 \%$ of the total amount of data. Due to this reason, the significance of the rest of the group of species observations is not so notable due to the relatively small number (Alces alces $P=0.099$, Lepus europaeus $P=0.86$, Sus scrofa (group) $P=0.16$ Sus scrofa (alone) $P=0.39, P=$ Small predators 0.15 , Large predators $P=0.31$ ). 
The diagram (Fig. 4) was drawn by combining three years of data collected in six observation lines. The median of the number of footprints indicated by large and medium size mammals on the roads was lower than in the control. This shows that the number of footprints on the forest roads is relatively small.

TABLE III

FOREST ROAD EFFECT ON MOVEMENT OF DIFFERENT SPECIES (P VALUES)

\begin{tabular}{|l|c|c|c|}
\hline Species & $\begin{array}{c}\text { Cont._1 } \\
\text { Road_1 }\end{array}$ & $\begin{array}{c}\text { Control_2 } \\
\text { Road_2 }\end{array}$ & $\begin{array}{c}\text { Control_3 } \\
\text { Road_3 }\end{array}$ \\
\hline Alces alces & 0.32 & 0.51 & 0.42 \\
\hline $\begin{array}{l}\text { Capreolus } \\
\text { capreolus }\end{array}$ & 0.43 & 0.34 & 0.14 \\
\hline Lepus europaeus & 1 & 0.42 & - \\
\hline Sus scrofa (group) & 0.39 & 0.27 & 0.27 \\
\hline Sus scrofa (alone) & 0.46 & 0.23 & 0.73 \\
\hline Small predators & 0.55 & 0.24 & 0.63 \\
\hline Large predators & 0.74 & 0.74 & 0.42 \\
\hline
\end{tabular}

Having summarized the observations carried out within all years of the survey without identifying the species, it was determined that there is a significant difference between the observed number of footprints on the forest roads and firebreaks $(P=0.001)$. A total of 63 observations for each group of animals was carried out in several years, and performed on different observation sites were used. The deviation of data was evaluated by t-test analysis of the data set. The results of the test led to the conclusion that there is a significant difference between the observed number of footprints left on the firebreaks and forest roads $(P$ value $<0.01)$.

\section{DISCUSSION}

On the whole, all the data of the observations in accordance with the year they were complied and the species they represented were summarized. From 529 observations $69 \%$ were recognized on the forest firebreaks, $31 \%$, in turn, were observed on the forest roads. It initially showed the effects of forest roads on the movement and migration of animals therefore it can be considered to be a restrictive factor which the animals do not willingly cross due to the reasons known better to the representatives of each species.

The data from the observation studies (Fig. 2-3, Tables I-III) indicate that forest roads inhibit the movements of large and medium size forest mammals. Thus confirming the hypothesis of the study that the effect of forest roads on large and medium size mammal movement is significant $(P=0.001)$. The open field work observations over the years have shown that the results do not depend on the year of compilation of data (Table I). Thus further data processing was performed without identification of the particular observation time (years).

The acquired results indicated that if the data is divided taking the factor of species as the basis for the evaluation, there is no significant difference between the observed number of footprints on the firebreaks (control) and forest roads.

This is explained by the small number of observations for such species or groups as Lepus europaeus (low density of population) and large predators (large territory for one individual). In turn, Alces alces and Sus scrofa (group) observations were not made in 2014. With increasing number of observations of footprints, the value of $P$ (Capreolus capreolus $P=0.04)$ decreased. The relatively low $P$ values were found for Alces alces $P=0.099$ and small predators $P=0.15$. Despite the fact that Alces alces showed less number of observations as a small predator it still showed a lower $P$ value. The fact can be explained by the specific character of the species as for example its feeding habits. For small carnivores - roads are often an important place in their feeding as they feed on the remains of animals killed in road accidents. Feeding database of Nyctereutes procyonoides contains reptiles and amphibians [39], which inhabit the ditches along the road sides or are also killed in road accidents due to traffic [18], [19], [20]. Thus, compared with Alces alces, small predators suffer a less significant impact of forest roads.

The data compiled during the winter of 2014, due to scarce snow, pointed to the existence of large and medium size mammals living in the forest tract, which was attested by the footprints found both on firebreaks and on forest roads. The analysis of the data did not indicate any specific matches in the intensity of the movement. In fact, the animal movement in fresh snow is very limited, which could be explained by the potential threat from predators [40], the decline of the rhythm and activity of animal life caused by the presence of snow in the woods [41] or a rapid change in circumstances requires some adaptation period to resume a normal life [42].

Although the results of the study confirmed the significant impact of forest roads on the overall movement of animals within the forest tract, they also stated that they do not restrict their crossing, which is an important precondition for the further exchange of genes and the sustainable existence and survival of the large and medium size mammal population. 


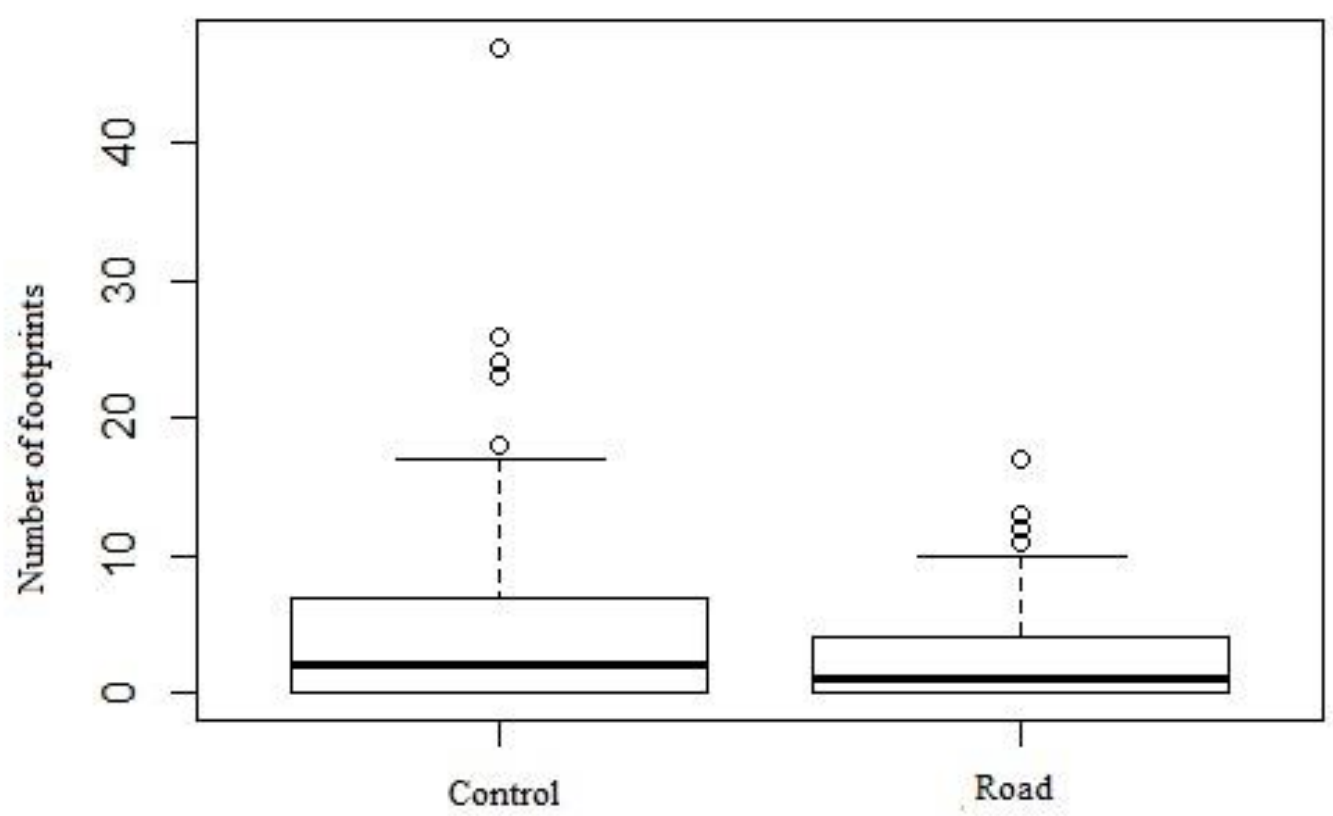

Fig. 4. Number of footprint showed by large and medium size mammals in road and control lines. The boxes represent the inter-quartile range and the median is indicated by the bold horizontal line. The vertical lines at the top of the boxes extend to the largest value within 1.5 times the interquartile range [23]. In this particular, case the vertical lines all reach the maximum value of the variables concerned.

In parallel to the performed observations, a significant feature was noticed during the field work - the animals more willingly choose to cross a forest road in definite places. As such observations and relevant conclusions were not the aim of the research, they will be addressed in the further course of research work to be able to evaluate the presence of different elements (distinct tree species or groups of tree species, road track, the trees on either side of the road forming definite canopy, the alternation of the linear road grade and the cross profile of the road, large dimension culverts, etc.) or nonexistence of (undergrowth not more than $1 \mathrm{~m}$ high, open forest tracks, road-sides with or without bushes and shrubs, etc.) on the migration and movements of the animals. This further research will make it possible to evaluate the influence of the reconstruction of already existing and the construction of planned forest roads on the migration and movement of animals. Taking into account and applying the facts acquired in course of the research, it will be possible to reduce the influence of the forest roads on the movement and migration of animals.

\section{REFERENCES}

1. Klavin̄š, A. Latvijas Daba: Enciklopēdija. [E-book] Riga: SIA "Gandrs", 2014. - [Accessed 04.04.2014.] Available: http://www.latvijasdaba.lv/ziditaji

2. Latvijas meža zeme gada beigās [Online]. Rīga (LV): Latvijas Republikas Centrālā Satistikas Pārvalde, November 2013 - [Accessed 17.03.2014.]. Available: http://www.csb.gov.lv/en/dati/latvijas-mezazeme-gada-beigas-30344.html

3. Par meža nozares (mežsaimniecības un kokrūpniecības) attīstības izvērtējumu: Informatīvais ziņojums [Online]. Rīga (LV): Ministry of Agriculture, August 2011 - [Accessed 21.03.2014.]. Available: polsis.mk.gov.lv/LoadAtt/file7065.doc

4. Forman, R. T. T., Alexander, L. E. Roads and their major ecological effects. Annual review of ecology and systematics, 1998, vol. 29, pp. 207-231. http://dx.doi.org/10.1146/annurev.ecolsys.29.1.207
5. Oehler, J. D., Litvaitis, J. A. The role of spatial scale in understanding responses of medium-sized carnivores to forest fragmentation. Canadian Journal of Zoology, 1996, vol. 74, No. 11, pp. 2070-2079. http://dx.doi.org/10.1139/z96-235

6. Mech, L. D., Fritts, S. H., Radde, G. L. et. al. Wolf distribution and road density in Minesota. Wildlife Society Bulletin, 1988, vol. 16, pp. 85-87.

7. Andrews, A. Fragmentation of habitat by roads and utility corridors: a review. Australian Zoologist, 1990, vol. 26, No. 3, pp. 130-141.

8. Brody, A. J., Pelton, M. R. Effects of roads on black bear movements in western North Carolina. Wildlife Society Bulletin, 1989, vol. 17, pp. 5-10.

9. Lovallo, M. J., Anderson, E. M. Bobcat movements and home ranges relative to roads in Wisconsin. Wildlife Society Bulletin, 1996, vol. 24, pp. 71-76.

10. Dyer, S. J., O'Neill, J. P., Wasel, S. M. et. al. Quantifying barrier effects of roads and seismic lines on movements of female woodland caribou in northeastern Alberta. Canadian Journal of Zoology, 2002, vol. 80, pp. 839-845. http://dx.doi.org/10.1139/Z02-060

11. Benítez-López, A., Rob Alkemade, R. et. al. The impacts of roads and other infrastructure on mammal and bird populations: a meta-analysis. Biological Conservation, 2010, vol. 143, No. 6, pp. 1307-1316. http://dx.doi.org/10.1016/j.biocon.2010.02.009

12. Newmark, W. D., Boshe, J. I., Sariko, H. I., Makumbule, G. K. Effects of a highway on large mammals in Mikumi National Park, Tanzania. African Journal of Ecology, 1996, vol. 34, pp. 15-31. http://dx.doi.org/10.1111/j.1365-2028.1996.tb00590.x

13. Rost, G. R., Bailey, J. A. Distribution of mule deer and elk in relation to roads. Journal of Wildlife Management, 1979, vol. 43, pp. 634-641. http://dx.doi.org/10.2307/3808741

14. Tigas, L. A., Van Vuren, D. H., Sauvajot, R. M. Behavioral responses of bobcats and coyotes to habitat fragmentation and corridors in an urban environment. Biological Conservation, 2002, vol. 108, pp. 299-306. http://dx.doi.org/10.1016/S0006-3207(02)00120-9

15. Summers, P. D., Cunnington, G. M., Fahrig, L. Are the negative effects of roads on breeding birds caused by traffic noise? Journal of Applied Ecology, 2011, vol. 48, No. 6, pp. 1527-1534. http://dx.doi.org/10.1111/j.1365-2664.2011.02041.x

16. Kociolek, A. V., Clevenger, A. P. Effects of Paved Roads on Birds: A Literature Review and Recommendations for the Yellowstone to Yukon Ecoregion. Alberta: Yellowstone to Yukon Conservation Initiative Society Canmore, 2009. 35 p.

17. Kociolek, A. V., Clevenger, A. P., Clair, C. C. S., Proppe, D. S. Effects of Road Networks on Bird Populations. Review. Conservation Biology, 2011, vol. 25, No. 2, pp. 241-249. 
http://dx.doi.org/10.1111/j.1523-1739.2010.01635.x

18. Ashley, E. P., Robinson, J. T. Road mortality of amphibians, reptiles and other wildlife on the long point causeway, Lake Erie, Ontario. Canadian Field-Naturalist, 1996, vol. 110, No. 3, pp. 403-412.

19. Woltz, H. W., Gibbs, J. P., Ducev, P. K. Road crossing structures for amphibians and reptiles: Informing design through behavioral analysis. Biological Conservation, 2008, vol. 141, No. 11, pp. 2745-2750. http://dx.doi.org/10.1016/j.biocon.2008.08.010

20. Glista, D. J., Devault, T. L., Dew, J. A. Vertebrate road mortality predominantly impacts amphibians. Herpetological Conservation and Biology, 2007, vol. 3, No. 1, pp. 77-87.

21. Fahrig, L., T. Rytwinski. Effects of roads on animal abundance: an empirical review and synthesis. Ecology and Society, 2009, vol. 14, No. 1, pp. 381-386.

22. Lysko, A., Cyglicki R., Dusza E. et. al. Spatial analysis of road conflicts with NATURA 2000 areas in Poland. The Problems of Landscape Ecology, 2010, pp. 381-386.

23. Jędrzejewski, W., Nowak, S., Kurek, R., Mysłajek, R.W., Stachura, K., Zawadzka, B., Pchalek, M. Animals and roads. Methods of mitigating the negative impact of roads on wildlife. Białowieża: Mammal Research Institute Polish Academy of Sciences, 2009.

24. Roger, E., Laffan, S.W., Ramp, D. Road impacts a tipping point for wildlife populations in threatened landscapes. Popul. Ecol., 2009, vol. 53, pp. 215-227. http://dx.doi.org/10.1007/s10144-010-0209-6

25. Lesbarreres, D., Fahrig, L. Measures to reduce population fragmentation by roads: what has worked and how do we know? Trends Ecol Evol, 2012, vol. 27, pp. 374-380. http://dx.doi.org/10.1016/j.tree.2012.01.015

26. Jaeger, J. A. G., Bowman, J., Brennan, J. et al. Predicting when animal populations are at risk from roads: an interactive model of road avoidance behavior. Ecol Model, 2005, vol. 185, pp. 329-348. http://dx.doi.org/10.1016/j.ecolmodel.2004.12.015

27. Rhodes, J. R., Lunney, D., Callaghan, J. et al. A Few Large Roads or Many Small Ones? How to Accommodate Growth in Vehicle Numbers to Minimise Impacts on Wildlife. PLoS ONE, 2014, vol. 9, No. 3, e91093. http://dx.doi.org/10.1371/journal.pone.0091093

28. Meisingset, E. L., Loe, L. E., Brekkum, Ø. et al. Red deer habitat selection and movements in relation to roads. The Journal of Wildlife Management, 2013, vol. 77, pp. 181-191.

http://dx.doi.org/10.1002/jwmg.469

29. Hewison, A. J. M., Vincent, J. P., Joachim, J. et.al. The effects of woodland fragmentation and human activity on roe deer distribution in agricultural landscapes. Canadian Journal of Zoology, 2001, vol. 79, No. 4, pp. 679-689. http://dx.doi.org/10.1139/z01-032

30. Lesmerises, R. Ouellet, J. P., Dussault, C. et.al. The influence of landscape matrix on isolated patch use by wide-ranging animals: conservation lessons for woodland caribou. Ecology and Evolution, 2013, vol. 3, No. 9, pp. 2880-2891. http://dx.doi.org/10.1002/ece3.695

31. Jędrzejewski, W., Jędrzejewska, B., Andersone-Lilley, A., et. al. Synthesizing wolf ecology and management in Eastern Europe similarities and contrasts with North America. In: The world of wolves. New perspectives on ecology, behaviour and management. University of Calgary Press, Calgary, 2010, pp. 207-233.

http://dx.doi.org/10.1371\%2Fjournal.pone.0076454

32. Ozolins, J., Pupila, A., Andersone-Lilley, Z. et. al. Wolf population responses to the intensive control by hunting in Latvia. In: 1st European Congress of Conservation Biology, Eger, Hungary, 2006.

33. Ozoliňš, J., Pupila, A., Ornicāns, A. et.al. Lynx management in Latvia: population control or sport hunting? In: Economic, social and cultural aspects in biodiversity conservation. Press of the University of Latvia, Riga, 2008, pp. 59-72.

34. Kawata, Y., Ozolins, J. and Andersone-Lilley, Z. An Analysis of the Game Animal Population Data from Latvia. Baltic Forestry, 2008, vol. 14, No. 1 , pp. $75-86$.

35. Kaczensky, P., Chapron, G., von Arx M., Huber, D., Andrén, H., Linnell, J. Status, management and distribution of large carnivores bear, lynx, wolf \& wolverine - in Europe. European Commission, 2013, pp. 35-36, pp. 93-95, pp. 159-161.
36. Huijser, M. P., Bergers, P. J. M. The efect of roads and traffic on hedgehog (Erinaceus europaeus) populations. Biological Conservation, 2000 , vol. 95 , pp. $111-116$. http://dx.doi.org/10.1016/S0006-3207(00)00006-9

37. 2013.-2014. gadu kalendārā ziema - viena no siltākajām un ar plānāko sniega segu 21. gadsimtā [Online]. Rīga (LV) : Latvian Environment, Geology and Meteorology Centre, March 2014-[Accessed 04.03.2014.]. Available: meteo.lv/jaunumi/laika-apstakli/2013-2014-gadu-kalendaraziema-viena-no-siltakajam-un-ar-planako-snieg 2 id $=633 \&$ cid $=100$

38. Sokal, R. R., Rohlf, F. J. The Principles and Practice of Statistics in Biological Research. In: Biometry. W.H. Freeman and Company, New York, 4th Edition, 2012, 937 p.

39. Carr, K. Re: Nyctereutes procyonoides. In: Animal Diversity [Online]. Michigan: University of Michigan, Museum of Zoology, 2004 - [Accessed 01.04.2014.]. Available: http://animaldiversity.ummz.umich.edu/accounts/ Nyctereutes_procyonoides/

40. Koshkarev, B. P. Characteristics of snow leopard (Uncia uncia) movements in the Tien Shan. Int. Ped. Book of Snow leopards, 1984, vol. 4, pp. 15-21.

41. Garshelis, D. L., Pelton, M. R. Activity of Black Bears in the Great Smoky Mountains National Park. Journal of Mammalogy, 1980, vol. 61, No. 1, pp. 8-19. http://dx.doi.org/10.2307/1379952

42. Telfer, E. S., Kelsall, J. P. Adaptation of Some Large North American Mammals for Survival In Snow. Ecology, 1984, vol. 65, No. 6, pp. 1828-1834. http://dx.doi.org/10.2307/1937779

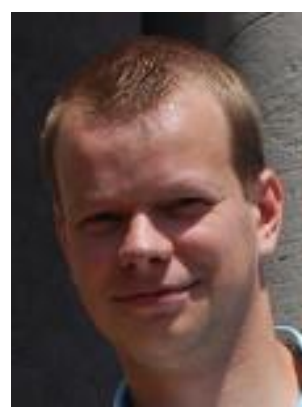

Mārcis Saklaurs, Latvia University of Agriculture, Forest Faculty - PhD student; Swedish University of Agricultural Science, the Faculty of Forest Science and Latvia University of Agriculture, Forest Faculty - Master (graduated in 2008)

Latvia University of Agriculture, RESEARCHER (Since 2013); SAMET Ltd., MEMBER OF THE BOARD. (Since 2013); EcoSylva Ltd (Woodmark Soil Association Certification Ltd), NATIONAL EXPERT AT FORESTRY IN CERTIFICATION PROCESS. (Since 2011); JENNAS farm. OWNER. (Since 2007); Ministry of Environmental Protection and Regional Development, Department of Nature Protection Division of the Species and Habitats Protection, DEPUTY HEAD OF DIVISION (2007-2011). Current research interest is to find solution between biological and economical sectors in development of the forestry.

SILVA FORTIS Society, MEMBER OF THE BOARD. (Since 2013); awarded a fellowship from company "IKEA" (2007); awarded a fellowship of foundation of Academician A. Kalniņš (2006).

Address: Smilšu 26-17, Salacgrīva, Latvia, LV-4033

Phone: +37126612520

E-mail: marcissaklaurs@inbox.lv

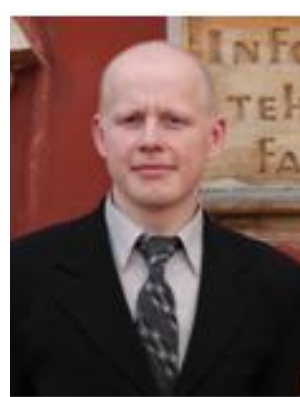

Raivis Baltmanis, Bc. sc. ing. (graduated in 2012), Master's degree student of Latvia University of agriculture of Faculty of Information Technologies. Current research interest is information technologies in the forestry.

Guest Assistant at Latvia University of agriculture (currently); research Assistant; researcher.

Address: Pumpura 7-52, LV-3001, Jelgava, Latvia

Phone: +37122045441 